\title{
A one per cent solution?
}

\section{San Francisco}

THE US semiconductor industry's leading corporations and a self-employed engineer, Gilbert P. Hyatt, are getting ready for multimillion dollar negotiations following last month's announcement that the US Patent Office has awarded Hyatt a patent covering virtually every microprocessor in use today. The patent runs from its effective filing date of 1970 , pre-dating the claim from the Intel Corporation team generally credited with creating the microprocessor. An Intel spokesman said last week that they are reviewing the patent, but have yet to decide its impact on the company or whether Intel would challenge it.

Hyatt's strategy is crucial. Because patents are not self-enforcing, Hyatt will have to take on the semiconductor makers in order to receive payment. Last week, Hyatt claimed some early successes, saying that he has nearly completed licensing fee negotiations with one major electronics corporation and that several other companies are already waiting to do business with him. Although he will not name the amount of money he is asking, Hyatt says he is looking for "a reasonable royalty that won't be a burden".

But even modest fees may add up to large amounts of money if the patent's validity withstands legal challenge. Ironically, if questioned in court, the patent may benefit from the 20 years it spent under review. Lawyers will now find it hard to make new arguments but may attempt to narrow the patent's coverage to more specific types of microprocessors, or argue that Hyatt's claim is invalid because he did not actually transform the technology into working products.

Royalty fees in the semiconductor industry are typically one to five per cent of a company's revenues on that product.

According to Willis E. Higgins, a patent attorney familiar with the document, Hyatt is likely to ask for a fee of less than one per cent in hopes of avoiding a litigious response from the corporations. Even so, the inventor stands to become a multimillionaire. In addition to US claims, Hyatt also has the right to seek royalties from foreign companies for the microprocessors that they make, use or sell in the United States.

Hyatt developed his microprocessor at a small company called Micro Computer, Inc. that he founded in 1968, then dissolved in 1971. The engineer, who holds over 50 other patents, supports his research through consulting for the aerospace industry. This is his first profitable patent, and he says he plans to channel its proceeds into his current personal computer research, which involves a radical departure from current technology. As he matter-of-factly describes it. "Twenty-two years ago I developed the PC for the twentieth century. Now I'm working on the PC for the twenty-first century."

Elizabeth Schaefer

\section{ICL deal threatens research links}

London

THE British computer company ICL's continued involvement in collaborative European research projects is in question, thanks to the disquiet of other European companies over the sale of an 80 per cent holding in ICL to the Japanese company Fujitsu. The board of JESSI (the Joint European Submicron Silicon Initiative) will meet on 27 November, three days before the Fujitsu deal is finalized, to decide if ICL can remain a member.

JESSI was set up by a group of European computer companies to promote collaborative research on the fabrication of semiconductors, and so enable the European industry to compete with the United States and Japan.

ICL is not heavily involved in JESSI projects, as the company obtains semiconductors from Fujitsu. But a spokesman rejects the accusation that ICL will become an outpost of the Japanese industry, not entitled to participate in European projects: "We continue to regard ourselves as a European-based company". He adds that the JESSI committee with which ICL is most strongly connected, concerned with applications for semiconductor materials, has said that ICL should not be expelled.

The European Commission seems to be taking a softer line over ICL's involvement in some 40 projects within its ESPRIT information technology research programme. In any case, US companies already participate in several European Communities research projects.

Filippo Pandolfi, Commission vicepresident in charge of research, has said that projects must be reviewed case by case and that it will be for the partners involved in each to decide if they wish to continue collaborating with ICL.

JESSI officials also have a more immediate concern than the ICL question - last month's decision of the Dutch electronics company Philips to pull out of JESSI's advanced memory chip project, which accounts for about 20 per cent of JESSI spending.
The long and
winding road

\section{London}

As the attention of the world's environmental diplomats switches to negotiating a climate change convention, there seems to be a broad international consensus that the task must be finished in time for the United Nations conference on environment and development, due to take place in Brazil in 1992. But whether the convention should be an agreement with substantial measures to combat global warming or a bare-bones statement of concern is more contentious.

Now the Intergovernmental Panel on Climate Change (IPCC)'s report has been completed (see Nature 347, 9; 6 September 1990), the climate change circus moves to Geneva on 24 September, where government representatives will lay down the ground rules for the negotiations proper. These start in Washington in February 1991, at a meeting hosted by US President George Bush.

William Nitze, from the US Alliance to Save Energy, who helped begin the IPCC process during his time at the US State Department, believes anti-globalwarming measures must be incorporated into the initial convention: a more general agreement "just won't cut it", he says. West Germany and the Scandinavian nations are likely to back this position, but the current generation of US negotiators will aim for an agreement along the lines of the 1985 Vienna Convention, which simply stated international concern over the thinning ozone layer. Firm targets on emissions of ozone-depleting chemicals were agreed only later, under the 1987 Montreal Protocol

Stewart Boyle, from the UK Association for the Conservation of Energy, says that in the case of climate change there is no need for a two-stage process of convention followed by protocol. The Montreal Protocol had to wait for scientific review, he says, which in this case IPCC has already provided. But US determination to stress the uncertainties surrounding current climate predictions, despite their failure to water down significantly the conclusions of the IPCC report, may force negotiations into two stages.

The British negotiating team is preparing for an 'honest broker' role. The United Kingdom is one of relatively few countries so far committed to stabilizing carbon dioxide emissions (see Nature 345, 373; 31 May 1990), provided other countries play their part. But UK negotiators are determined not to let calls from some countries for the inclusion of rigid emission targets scupper the delicate convention negotiations.

Nitze says that the option of a more 